\title{
A rare case of sex reversal during puberty
}

\author{
${ }^{1}$ Division of Endocrinology, Department of Internal Medicine 1, Goethe-University Hospital, Frankfurt, Germany \\ 2Department of Urology, Markus-Krankenhaus, Frankfurt, Germany
}

\section{Background:}

Disorders of sexual development (DSD) are rare and, in particular in developed countries, they are predominantly diagnosed during early childhood. DSD show a wide variety of phenotypes and can be difficult to classify.

\section{Clinical Case:}

A 34-year-old refugee from Somalia was referred because of a suspected DSD. Due to ambiguous, but predominantly female external genitalia at birth he was classified and raised as a girl in Somalia, whereas his subjective gender identity has always been male. Puberty led to a significant virilization of the body but only to a very limited virilization of the external genitalia. The patient presented himself with an undoubtedly male-type body composition, a deep voice, an adequate androgenic hair distribution, ongoing androgenetic alopecia and no gynecomastia. External genitalia were ambiguous, but now predominantly male with micropenis and hypospadia glandis [fig1]. Small testes could be palpated in both labia, between which a small perineal orifice appeared.

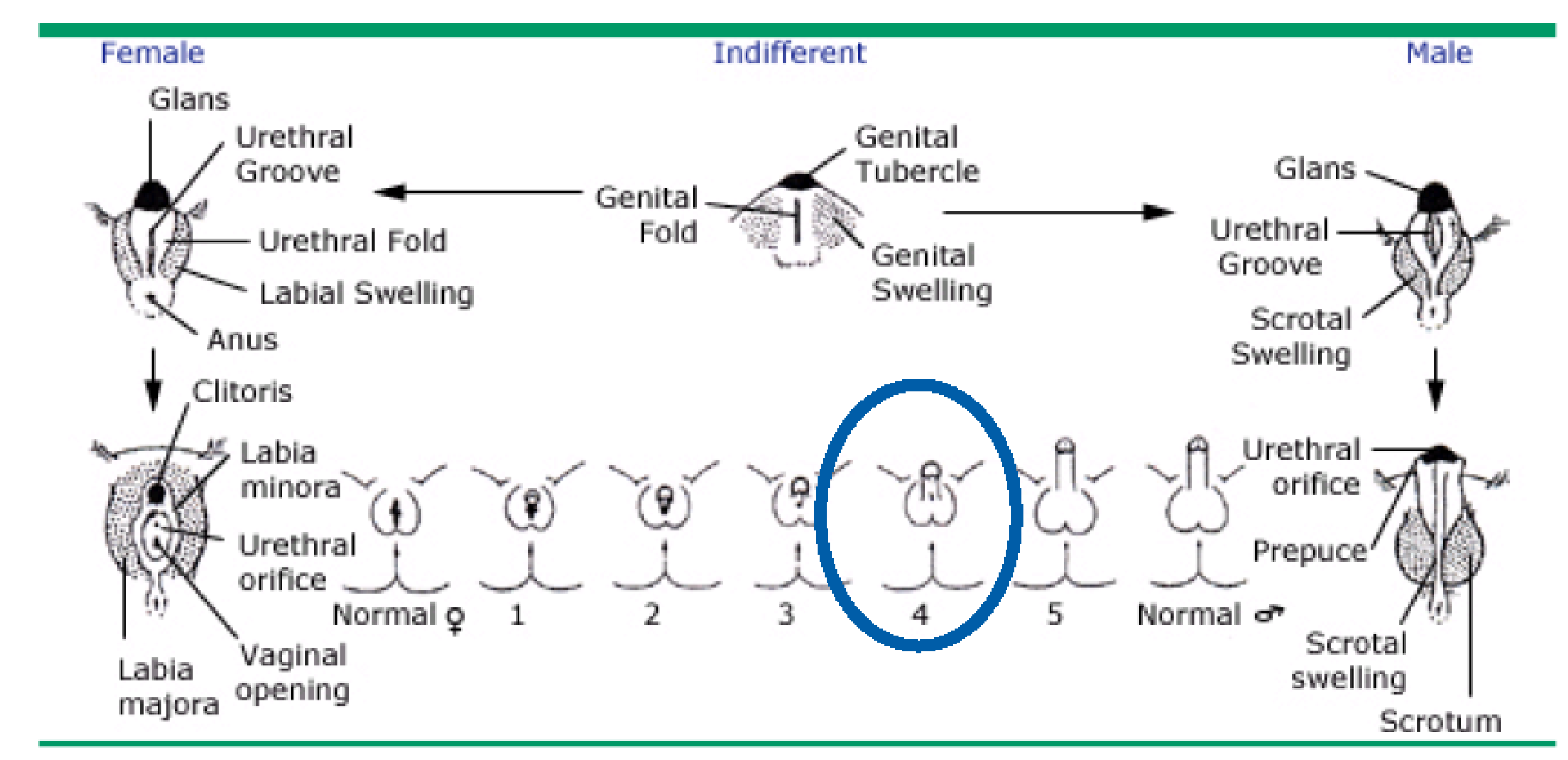

Fig 1: Prader's classification of grades of genital ambiguity (4); patient's finding marked by circle

Diagnostic laparoscopy did not show any female internal genitalia. Sex hormones lay within normal male ranges: $\mathrm{LH} 8.4 \mathrm{mE} / \mathrm{ml}$ (n 1.78.6), FSH $7.1 \mathrm{mE} / \mathrm{ml}$ (n 1.5-12.4), testosterone (T) 704 ng/dl (n 249836), dihydrotestosterone (DHT) $13.3 \mathrm{ng} / \mathrm{dl}$ (n 10-60), DHEAS $214.8 \mu \mathrm{g} / \mathrm{dl}$ ( $\mathrm{n} 160-449)$, androstenedione $3 \mathrm{ng} / \mathrm{ml}$ ( $\mathrm{n}$ 1.23-3.75). Estradiol level was borderline elevated (54 pg/ml, $\mathrm{n}$ 27.1-52.2), whereas Müllerian inhibiting hormone was remarkably increased (35.48 ng/ml, n 1.5-4.3) [table 1]. Chromosome analysis showed a regular male karyotype 46,XY.ishYp11.3(SRY+) [fig2]. Highly increased T/DHT-ratio of 54 (n 8-16) [fig 3] in combination with the masculinization defect strictly limited to external genitalia without gynecomastia led to the clinical diagnosis of steroid 5 alphareductase 2 deficiency (SRD)

\section{Conclusions:}

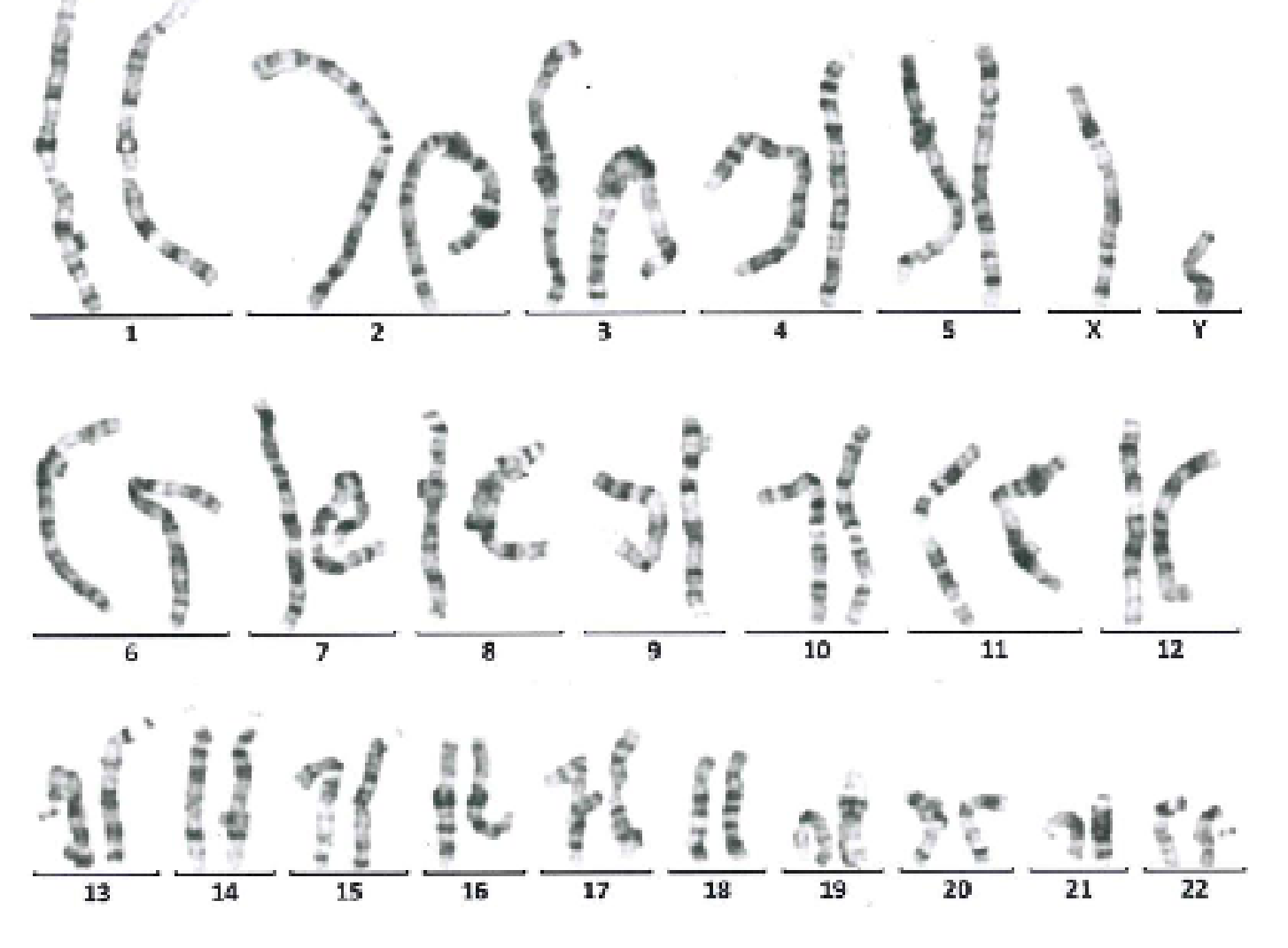

Fig 2: karyogram

\begin{tabular}{llll} 
Androstenedione & $3 \mathrm{ng} / \mathrm{ml}$ & $\mathbf{8}-1.23-3.75$ \\
Estradiol & $\mathbf{5 4} \mathbf{~ p g} / \mathbf{m l}$ & $\mathbf{2 7 . 1} \mathbf{5 2 . 2}$ \\
\hline Müllerian inhibiting & $\mathbf{3 5 . 4 8} \mathbf{~ n g} / \mathbf{m l}$ & $\mathbf{1 . 5} \mathbf{4 . 3}$ \\
\hline
\end{tabular}

hormone

Table 1: hormone levels

SRD is an autosomal recessive, $46, X Y$ disorder of sexual development leading to an impaired virilization during embryogenesis due to defective conversion of $\mathrm{T}$ to $\mathrm{DHT}$, which as the most potent androgen is essential for full masculinization of the external genitalia. In affected subjects, 5-alpha-reductase activity is reduced in genital skin fibroblasts. Clinical presentation is highly variable from almost entirely female to almost entirely male external genitalia. $(1,2)$ Pubertal increase in $T$ can be sufficient for virilization of the remainder body at the time of expected puberty as seen in our patient. Consanguinity of patient's parents suggests a homozygous mutation in the SRD5A2 gene and a molecular genetic analysis is ongoing in order to identify the mutation. Over 50 different mutations have been described in the past (3).

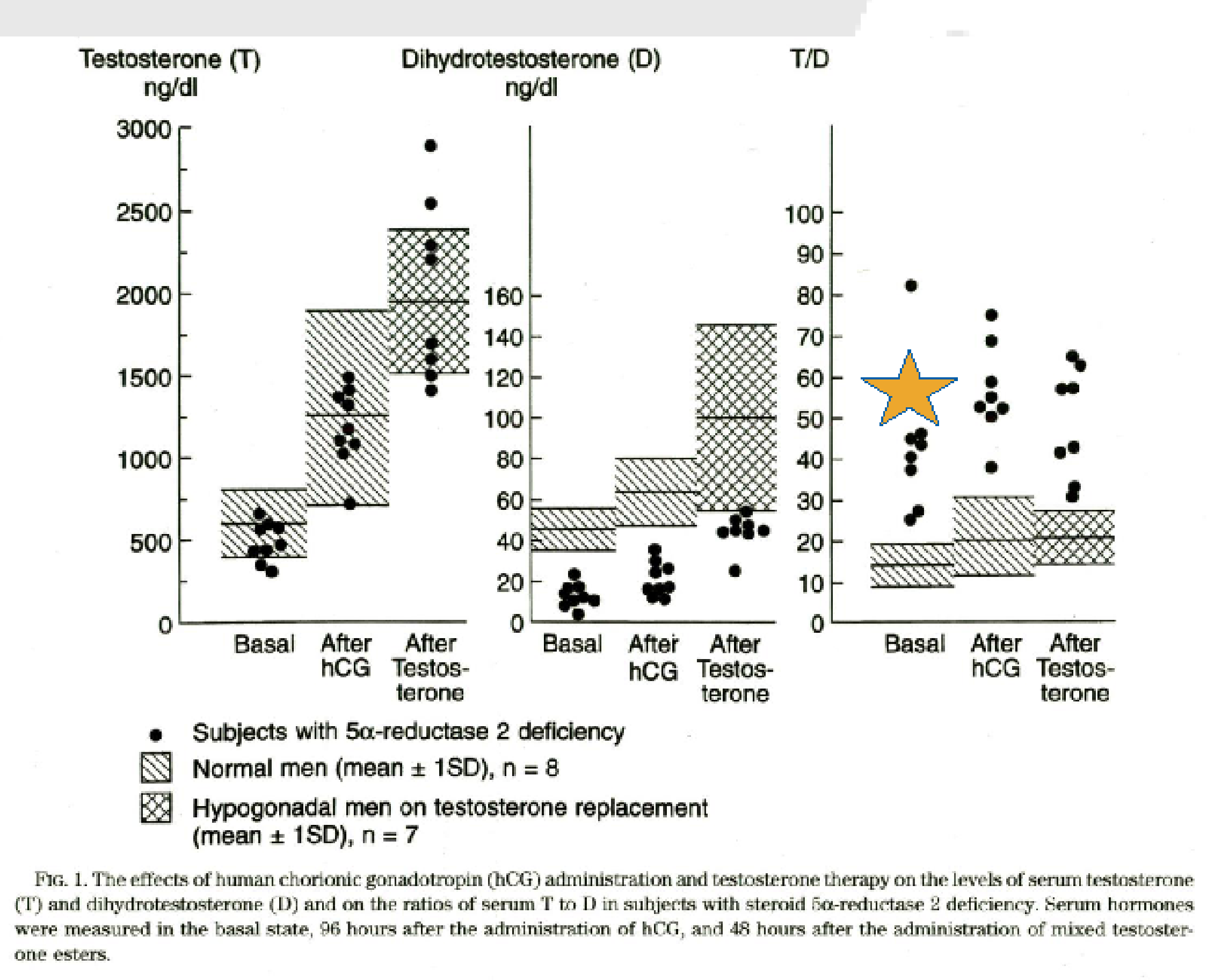

Fig 3: remarkably elevated T/DHT-ratio in patients with 5a-reductase 2 deficiency (5); patient's findings added as

This case of a rare DSD elucidates impressively how an enzyme deficiency affects the mechanisms of androgen action in the process of sexual differentiation.

\section{References:}

(1) Sinnecker GH et al. Phenotypic classification of male pseudohermaphroditism due to steroid 5 alpha-reductase 2 deficiency. Am J Genet. 1996; 63;223-230.

(2) Wilson JD et al. Steroid 5 Alpha-Reductase 2 Deficiency. Endocr. Rev. 1993;14;577-93.

(3) The Human Gene Mutation Database at the Institute of Medical Genetics in Cardiff.

4) White PC, Speiser PW. Congenital adrenal hyperpasia due to 21-hydroxylase deficiency. Endocr Rev. 2000; 21:245-291.www.hgmd.cf.ac.uk/ac/index.php

(5) Mendonca BB et al. Male Pseudohermaphroditism Due to Steroid 5a-Reductase 2 Deficiency. Medicine (Baltimore). 1996 Mar;75):64-76. 